Calsbeek, H., Rijken, M., Dekker, J., Berge Henegouwen, G.P. van. Disease characteristics as determinants of the labour market position of adolescents and young adults with chronic

digestive disorders. European Journal of Gastroenterology \& Hepatology: 2006, 18(2), 203-209

\begin{tabular}{|l|l|}
\hline $\begin{array}{l}\text { Postprint } \\
\text { Version }\end{array}$ & 1.0 \\
\hline $\begin{array}{l}\text { Journal website } \\
\text { http://meta.wkhealth.com/pt/pt-core/template- } \\
\text { journal/lwwgateway/media/landingpage.htm?an=00042737-200602000-00014 }\end{array}$ \\
\hline Pubmed link & http://www.ncbi.nlm.nih.gov/pubmed/16394803 \\
\hline DOI & \\
\hline
\end{tabular}

This is a NIVEL certified Post Print, more info at http://www.nivel.eu

\title{
Disease characteristics as determinants of the labour market position of adolescents and young adults with chronic digestive disorders
}

\author{
Hiske CALsbeeK, MieKe RiJKen, JoOst DeKKer B AND GeRARD P. VAN BERGE \\ HENEGOUWEN
}

\section{INTRODUCTION}

Due to advances in medical knowledge and treatment possibilities, the number of children with a life-threatening or chronic illness reaching adulthood has enormously increased in past decades. As a result, the interest in the influence of disease and treatment on the course of life of these patients has intensified [1]. Research on long-term effects of having a chronic illness during the transition from adolescence to adulthood is relatively new and, with regard to digestive disorders, often involves inflammatory bowel disease (IBD) patients [2-5]. Generally, these studies address the effects of IBD on the quality of life of children and adolescents, such as the impact on social functioning (family, friends), physical functioning (body complaints, motor functioning), and psychological functioning (depression, anxiety). So far, little is known about the influence on job prospects of being diagnosed with a chronic digestive disorder during adolescence. Most knowledge on labour market implications is available from studies in adult populations [6]. In general, the labour market position of people with a chronic disease can be characterized as problematic, with regard to getting a job as well as job continuation. Indications exist that young IBD patients also have to face difficulties in trying to enter the employment market [7-9]. Furthermore, a recent casecontrol study [10] showed that work disability and sick leave are more prevalent in IBD patients compared with controls, especially in younger patients. Also, in the authors' own study [11] in a younger target group, IBD patients and patients with chronic liver diseases appeared to have less employment prospects compared with population controls. Additionally, chronic liver disease patients reported more often the need for reeducation in order to find a job. A possible explanation for variations between and within several chronic digestive disorders regarding labour participation is the extent of burden of disease. According to Boonen et al. [10] the course of disease in IBD patients can be considered an important factor of chronic work disability and sick leave. Correspondingly, some disease burden indicators (e.g. disability in endurance, medical treatment and diet adherence) were identified as risk factors for school and leisure activities of adolescent patients with chronic digestive disorders (data not shown). This study aims to investigate whether labour participation in patients with chronic digestive disorders is dependent on disease characteristics such as type of diagnosis and disease burden characteristics. The present study elaborates on a study reported previously in which several social consequences of chronic digestive disorders have been described [11]. 
Calsbeek, H., Rijken, M., Dekker, J., Berge Henegouwen, G.P. van. Disease characteristics as determinants of the labour market position of adolescents and young adults with chronic

digestive disorders. European Journal of Gastroenterology \& Hepatology: 2006, 18(2), 203-209

\section{METHODS}

\section{Sample}

The sample included 622 patients (age 15-24 years), suffering from inflammatory bowel disease (IBD) ( $n=274)$, chronic liver diseases $(n=78)$, and congenital digestive disorders such as anorectal malformations $(n=104)$, food allergy $(n=77)$, or celiac disease $(n=89)$. Subjects were recruited via 25 medical specialists in 11 academic and specialized hospitals, using the following criteria: being diagnosed within one of the five diagnostic categories stated by a certified medical specialist, illness duration of at least 6 months, age from 15 to 24 years, being non-institutionalized, being aware of diagnosis, not terminally ill, being mentally capable to participate and mastering the Dutch language sufficiently. In classifying patients, the International Classification of Diseases, 10th revision [12] was used. Extra patients with coeliac disease were recruited through a patient organization, using the same criteria (diagnosis had to be confirmed by at least one small-bowel biopsy). There was no selection on illness activity or severity of complaints and disability. The mean response was $55 \%$, ranging from $47 \%$ in chronic liver disease patients and in patients with congenital digestive disorders, to $66 \%$ in the IBD group. The sample also included population controls ( $n=248$; response rate, 55\%). Controls were randomly recruited from the patient files of 147 general practitioners of participating patients. Except for a diagnosis within one of five diagnostic categories, the same recruitment criteria were used as for patients. The general practitioners were provided with a random set of three different letters of the alphabet on the basis of which they were requested to select three controls with surnames starting with the indicated letters and fitting the specified criteria. In order to increase the response, non-respondents were up to three times reminded of the study. The study was approved by all participating hospitals' ethical committees. All respondents gave written informed consent.

\section{Measurement}

Data were obtained by a postal survey. Gender, age, socioeconomic status, age of diagnosis and comorbidity were measured as background variables. Socio-economic status was operationalized by the highest education of one of the parents or carers on a seven-point scale, ranging from (1) no education or primary school to (7) university training. Comorbidity (other chronic diseases) was dichotomized. Labour participation was assessed by the number of hours employed per week. According to national classifications [12,13], four categories were used: $0-11,12-19,20-34$ and $35 \mathrm{~h}$ or more. Following the common definition of labour participation [13,14], a working week of less than $12 \mathrm{~h}$ was considered as not participating in the labour market. Therefore, the $0-11$ category was interpreted as not having a paid job. Also, a working week of $35 \mathrm{~h}$ or more was interpreted as having a fulltime job, and both categories of 12-19 and 20-34 h as having a part-time job. Subsequently, three dichotomous variables were composed: having a paid job (from $12 \mathrm{~h}$ a week) versus not having a paid job (0-11 h); having a paid job (from $20 \mathrm{~h}$ a week) versus not having a paid job or having a small parttime job (0-19 h); and having a full-time job (35 h or more) versus not having a paid job or having a part-time job (0-34 h). In order to interpret labour participation properly, pupils and students - those who reported attending daytime classes (e.g. secondary school, high school or vocational training) - were excluded from further analyses. Burden of disease was quantified by a set of eight characteristics: physical complaints, anxiety, depression, disability in endurance, hospitalization, use of medication, the need to adhere to a diet and nocturnal toilet use. Physical complaints were measured by a set of 23 items (e.g. referring to abdominal pain, diarrhoea, skin rash, fatigue and flatulence). This list was compiled on the basis of medical literature and information provided by the participating physicians and by patients' associations. All items were scored on a three-point scale from (0) no trouble to (2) much trouble during the past 4 weeks, resulting in a total score between 0 and 46. Anxiety and depression were measured by the Hospital Anxiety and Depression Scale [15,16]. Both measures consisted of seven items (Cronbach's alpha values, 0.79 and 0.72 , respectively), and were scored on a four-point scale. Disability in endurance 
Calsbeek, H., Rijken, M., Dekker, J., Berge Henegouwen, G.P. van. Disease characteristics as determinants of the labour market position of adolescents and young adults with chronic

digestive disorders. European Journal of Gastroenterology \& Hepatology: 2006, 18(2), 203-209

was assessed by a scale derived from the Children Quality of Life questionnaire (TACQOL) [17] consisting of three items (Cronbach's alpha, 0.86) (e.g. 'did you have difficulties with running the past 4 weeks'). These items were scored on a three-point scale from (0) no difficulties to (2) often difficulties (scale range, 0-6). Hospitalization was measured by two items: 'number of times hospital admission' and 'number of times undergoing surgery' (Cronbach's alpha, 0.70 ), converted to a 12-point scale. Daily use of medication was assessed by the number of times of medication intake per day in the time of the survey, from zero to four times or more often. The need to diet adherence was measured on a four-point scale, from (0) no diet at all to (3) strict diet adherence. Finally, nocturnal toilet use refers to urge to go to the toilet at night for defecation, measured on a five-point scale ranging from (0) never to (4) always.

\section{Statistical analyses}

Analyses of variance or chi-square tests were used to test differences between groups with regard to the background characteristics. In analysis of variance, Scheffe' or Tamphanes T2 procedures (respectively homogeneous groups and non-homogeneous groups) were applied as post-hoc tests. Descriptive statistics of labour participation were computed in student respondents as well as in non-student respondents. Subsequently, in non-student participants the several diagnostic groups were compared with the control group. For this purpose, logistic regression procedure was performed with age, gender and socioeconomic status added as covariates. Next, mean scores on burden of disease measures were computed in the diagnostic groups and compared with the control group (non students), applying analyses of variance (with age, gender and socio-economic status as covariates). Two pre-analyses were performed in non-student patients. First, relationships between burden of disease measures and labour participation were explored by applying bivariate logistic regression analyses. Second, Pearson correlation coefficients were computed between burden of disease measures in order to examine mutual correlations. Finally, multivariate logistic regression analyses of labour participation on background characteristics and burden of disease measures were performed, again in non-student patients. In these analyses, a stepwise (forward) selection procedure was employed, to prevent important variables from exclusion from the model as a result of mutual correlations. The likelihood-ratio test was used for selecting variables from the model $[18,19]$ (alpha level, 0.05).

\section{RESULTS}

Table 1 presents the background characteristics of the respondents. With regard to all characteristics, differences were found between several diagnostic groups. Furthermore, IBD patients were found to be significantly older than the controls. The age of diagnosis and the duration of disease obviously showed large variations between several diagnostic groups. Only the mean age of diagnosis regarding chronic liver diseases and food allergy appeared to be the same (between the ages of 11 and 12 years). Except for the food allergy group, approximately $30 \%$ of the patients reported comorbidity. Over $80 \%$ of the food allergy patients reported comorbidity (mainly other allergic diseases often associated with food allergy), which resulted in significant differences with the other diagnostic groups. As being unemployed or having a limited part-time job (up to $19 \mathrm{~h}$ ) can be considered to have a more severe impact on the social life in young adults who have finished their daytime education, a distinction was made between students and non-students. Approximately $40 \%$ of the sample $(n=331)$ reported to have finished daytime classes such as secondary school, highschool or vocational training. Looking at this non-student group (Table 2), relatively high percentages of patients with IBD, chronic liver disease and food allergy not participating on the labour market (0-11 h) were found. In addition, having a full-time job (35 working hours or more per week) was mostly found in patients with coeliac disease or congenital digestive disorders, and in controls. Controlling for age, gender and socio-economic status, patients with IBD and chronic liver diseases were found to differ negatively from the controls in all 
Calsbeek, H., Rijken, M., Dekker, J., Berge Henegouwen, G.P. van. Disease characteristics as determinants of the labour market position of adolescents and young adults with chronic

digestive disorders. European Journal of Gastroenterology \& Hepatology: 2006, 18(2), 203-209

categories of labour participation. In addition, Table 2 shows a comparison on labour participation between our control group and national statistics [13,14,20]. Apart from a slight over-representation in the lowest category and under-representation in the 12-19 h category, the percentages in the control group are almost similar to the general population. Table 3 presents the mean scores on burden of disease measures for each diagnostic group and control group (non-students). All diagnostic groups showed higher scores on at least one measure compared with the control group (after controlling for socio-demographic characteristics). Patients with chronic liver diseases and IBD were found to experience more physical complaints, more disability in endurance, were hospitalized more frequently, used more medication, had to watch their food intake more often and had more frequent nocturnal toilet use than controls. Furthermore, chronic liver disease patients reported more anxiety and depression. Food allergy patients also appeared to experience more physical complaints, disability in endurance, use of medication and, obviously, the need for diet adherence. A remarkably high score was found on physical complaints. Patients with coeliac disease and congenital digestive disorders were found to report significantly higher scores regarding the need to diet adherence and hospitalization, respectively. Bivariate logistic regression analyses revealed several burden of disease measures to be negatively associated with labour participation: daily medication intake and nocturnal toilet use appeared to relate negatively to labour participation, regardless of the number of working hours per week (Table 4). In addition, disability in endurance was found to be negatively associated with having a fulltime job. In order to assess mutual variance, Pearson correlations coefficients were computed between burden of disease measures in non-student patients (data not shown). They ranged from 0.01 to 0.65 , showing several mutual correlations. Strong correlations $(r \leq 0.50)$ were found between anxiety and depression, physical complaints and disability in endurance, and between physical complaints and anxiety. Finally, a stepwise multivariate logistic regression analysis of each labour participation measure on background characteristics and burden of disease measures was performed in non-student patients (Table 5). Apart from socioeconomic status and gender, nocturnal toilet use and medication intake appeared to be significant factors in the regression models. Nocturnal toilet use was found to be negatively associated with being employed from $12 \mathrm{~h} /$ week, as well as being employed from $20 \mathrm{~h} /$ week. In other words, with a more frequent nocturnal toilet use, patients are less likely to find a job or to be employed from $20 \mathrm{~h} /$ week. Furthermore, medication intake was found to relate negatively to a full-time position.

\section{[TABLE 1] [TABLE 2] [TABLE 3] [TABLE 4] [TABLE 5]}

\section{DISCUSSION}

Labour participation was studied in non-students (approximately $40 \%$ of our sample) bacause being unemployed or having a limited part-time job (up to $19 \mathrm{~h}$ ) in this group can be considered to have a more severe impact on social life. Young patients with IBD and chronic liver diseases were found to be unemployed or involved in a part-time job more often than healthy peers. These results support previous findings in IBD patients [7-9]. Looking at the burden of disease, it appeared that patients with IBD and chronic liver diseases have to cope with more physical complaints, disability in endurance, hospitalization, daily medication intake, need to diet adherence and nocturnal toilet use than healthy peers. Besides, chronic liver disease patients experience more anxiety and depression. Bivariate regression analyses of labour participation and burden of disease revealed several burden of disease measures to be negatively associated with labour participation, such as medication intake, nocturnal toilet use and disability in endurance. Adding background characteristics to the regression models, medication intake and nocturnal toilet use emerged as significant risk factors. Therefore, the extent of (daily) medication intake and (nocturnal) toilet use can be considered important risk factors for a reduced labour market position of young adults with chronic digestive 
Calsbeek, H., Rijken, M., Dekker, J., Berge Henegouwen, G.P. van. Disease characteristics as determinants of the labour market position of adolescents and young adults with chronic

digestive disorders. European Journal of Gastroenterology \& Hepatology: 2006, 18(2), 203-209

disorders. Apparently, young patients with IBD or chronic liver diseases are more at risk for a worse labour market position when nocturnal toilet use and frequent medication intake trespass on their daily life. In this respect, our results supply a concrete basis for possible immaterial work adjustments, such as possibilities for schedule modifications or for more breaks. In the direction of physicians it is recommended to recognize the possible impact of IBD and chronic liver diseases on labour participation and to discuss this subject with their patients. An important point of consideration concerns the response rates, in both the patient and control groups 55\%. The mean age in the respondent patient group (20 years) appeared to be one year younger, compared with the non-respondent group (21 years). In addition, the respondent group consisted of more females (58\%) than the non-respondent patients (50\%). We do not have information about the reasons for non-response. The same pattern concerning age and gender was found in the control group, with equal mean ages and more females in respondents (56\%) than in non-respondents (43\%). As almost every inhabitant in The Netherlands is registered with a general practitioner, recruitment by general practitioners is an optimal procedure to end with a representative control group. The recruitment of patients by physicians in academic and specialized centres, on the other hand, might create the impression that more seriously ill patients were selected. However, there is strong evidence that adolescents and young adults with chronic digestive disorders who are not treated there have been seen at least once in an academic or specialized centre, serving as a secondary or tertiary hospital, and, as a result, have been enclosed in the hospitals' registrations that were used to select the patients for this study. As for IBD, it is more likely that patients are seen in peripheral hospitals. To test our assumption that a recruitment procedure via academic hospitals does not necessarily results in a selection of more seriously ill patients, IBD patients recruited by physicians in academic hospitals and participating patients recruited via the IBD Registry South Limburg [20] were compared on comorbidity, illness duration and burden of disease. Results from this comparison (data not shown) support our assumption that we did not select the more seriously ill patients. To verify the representativeness of the control group, data on labour participation and other social aspects, such as educational level and relationships, were compared with national statistics, resulting in almost similar outcomes. Therefore, apart from small deviations in age and gender, the findings in this study can be considered rather representative. Second, the cross-sectional character of the study can also be considered a limitation. Because of this, relationships between burden of disease and labour participation theoretically can be interpreted in both directions and therefore do not necessarily express causal conclusions. However, looking at the nature of the significant burden of disease characteristics, the described direction is the most reasonable. Nevertheless, it would be worthwhile to conduct a follow-up study in the same IBD and chronic liver disease patients to gain more insight in the longterm effects on labour participation. Furthermore, the statistical analyses can use some reflection. Applying a stepwise selection procedure in regression analysis implies that, at any step in the procedure, the most important variable is selected on the basis of statistical terms (by producing the greatest change in log-likelihood relative to a model not containing the variable) [19]. In addition, our 'alpha' level of 0.05 is generally being considered very stringent, making it possible to exclude important variables from the model [19]. This is undesirable particularly in studying relatively new outcomes, when many possible covariates are collected and screened for significant associations. In such studies, an alpha range of $0.15-0.20$ is recommended [19]. Specifying an alpha value of 0.15 in our analyses indeed resulted in an extra burden of disease indicator (namely 'hospitalization'). In the present study, an alpha value of 0.05 was being maintained, resulting in two disease-related risk factors for a reduced labour market position. Finally, due to small numbers in the nonstudent subsample, only large effects could be shown. However, labour participation is a rather distal outcome measure, mediated by many personal and environmental factors. Nevertheless, in spite of the generally weak associations, some significant disease burden measures could be identified, which indicates that, apart from diagnosis and background 
Calsbeek, H., Rijken, M., Dekker, J., Berge Henegouwen, G.P. van. Disease characteristics as determinants of the labour market position of adolescents and young adults with chronic

digestive disorders. European Journal of Gastroenterology \& Hepatology: 2006, 18(2), 203-209

characteristics, disease burden in view of daily consequences does interfere with labour participation. It can be concluded that young patients with IBD or chronic liver diseases are less likely to participate in the labour market compared with population controls. Except for socio-economic status and gender, the extents of medication intake and nocturnal toilet use were identified as risk factors for a limited labour market position. Apart from the physical consequences of chronic digestive disorders, these additional effects deserve extra attention from gastroenterologists. It is recommended to recognize the possible impact of IBD and chronic liver diseases on labour participation and to discuss this subject with the patients in order to prepare them for possible labour market difficulties. In addition, these results supply a concrete basis for possible immaterial work adjustments, such as schedule modifications.

\section{REFERENCES}

1 Last BF, Grootenhuis MA, Destree-Vonk A, Heymans HSA. De ontwikkeling van een levensloop vragenlijst voor jongvolwassenen [The development of a course of life questionnaire for young adults]. Gedrag Gezondheid 2000; 1:23-30.

2 Engstrom I. Inflammatory bowel disease in children and adolescents: mental health and family functioning. J Pediatr Gastroenterol Nutr 1999; 28:s28-s33.

3 Decker JW. The effects of inflammatory bowel disease on adolescents. Gastroenterol Nurs 2000; 2:63-66.

4 Richardson G, Griffiths AM, Miller V, Thomas AG. Quality of life in inflammatory bowel disease: a cross-cultural comparison of English and Canadian Children. J Pediatr Gastroenterol Nutr 2001; 32:573-578.

5 Loonen HJ, Grootenhuis MA, Last BF, Koopman HM, Derkx BHF. Healthrelated quality of life of children with inflammatory bowel disease measured by a generic and a disease specific questionnaire. Acta Paediatr 2002; 3:348-354.

6 Baanders AN, Rijken PM, Peters L. Labour participation of the chronically ill. A profile sketch. Eur J Public Health 2002; 12:124-130.

7 Wyke RJ, Edwards FC, Allan RN. Employment problems and prospects for patients with inflammatory bowel disease. Gut 1998; 29: 1229-1235.

8 Mayberry MK, Probert C, Srivastava E, Rhodes J, Mayberry JF. Perceived discrimination in education and employment by people with Crohn's disease: a case control study of educational achievement and employment. Gut 1992; 33:312-314.

9 Mayberry JF. Impact of inflammatory bowel disease on educational achievements and work prospects. J Pediatr Gastroenterol Nutr 1999; 28:S34-S36.

10 Boonen A, Dagnelie PS, Feleus A, Hesselink MA, Muris JW, Stockbru“ gger RW, et al.

The impact of inflammatory bowel disease on labor force participation: results of a population sampled case-control study. Inflammatory Bowel Dis 2002; 6:382-389.

11 Calsbeek H, Rijken PM, Bekkers MJTM, Kerssens JJ, Dekker J, van Berge Henegouwen GP. Social position of adolescents with chronic digestive disorders. Eur J Gastroenterol Hepatol 2002; 14:543-549.

12 World Health Organization. ICD_10: international statistical classification of diseases and related health problems. Geneva: WHO; 1992.

13 Statistics Netherlands (CBS). Enque^te Beroepsbevolking 1998 [Inquiry working population 1998]. Voorburg/Heerlen: CBS; 1999.

14 Social and Cultural Planning Office of the Netherlands (SCP). Rapportage jeugd 2000 [Report on youth 2000]. Den Haag: SCP; 2000.

15 Zigmund AS, Snaith RP. The Hospital Anxiety and Depression Scale. Acta Psychiatr Scand 1983; 67:361-370.

16 Spinhoven P, Ormel J, Sloekers PPH, Kempen GIJM, Speckens AEM, Van Hemert AM. A validation study of the Hospital Anxiety and Depression Scale (HADS) in different groups of Dutch subjects. Psychol Med 1997; 27:363-370.

17 Verrips GH, Vogels AGC, Verloove-Vanhorick SP, Fekkes M, Koopman HM, Kamphuis $\mathrm{RP}$, et al. Health-related quality of life measure for children-the TACQOL. J Appl Therap 1998; 1/4:357-360.

18 Norus $\longleftarrow$ is MJ. SPSS/PC+ advanced statistics version 5.0. Chicago, IL: SPSS; 1992. 
Calsbeek, H., Rijken, M., Dekker, J., Berge Henegouwen, G.P. van. Disease characteristics as determinants of the labour market position of adolescents and young adults with chronic digestive disorders. European Journal of Gastroenterology \& Hepatology: 2006, 18(2), 203-209

19 Hosmer DW, Lemeshow S. Applied logistic regression. New York: John Wiley \& Sons; 1989.

20 Russel MGVM, Brummer R, Limonard C, Dorant E, Stockbrugger R.

Incidence and prevalence of inflammatory bowel disease in South Limburg, The

Netherlands. Neth J Med 1994; 45:A32 (abstract).

\section{TABLES}

Table 1 Background characteristics of patients and controls

\begin{tabular}{|c|c|c|c|c|c|c|c|}
\hline & $\begin{array}{c}\text { Intammatory } \\
\text { bowel disease } 0 \\
(n=274)\end{array}$ & $\begin{array}{l}\text { Orronic liver } \\
\text { disease (il) } \\
(n=78)\end{array}$ & $\begin{array}{c}\text { Congenital } \\
\text { digestive disorder (i) } \\
(n=104)\end{array}$ & $\begin{array}{l}\text { Food allergy (M) } \\
\qquad(n=77)\end{array}$ & $\begin{array}{l}\text { Coeliac disease (V) } \\
\qquad(n=89)\end{array}$ & $\begin{array}{c}\text { Control } \\
\text { group } \\
(n=248)\end{array}$ & Statistics \\
\hline \multicolumn{8}{|c|}{ Socio-demographic characteristics of patients and controls $(n=870)$} \\
\hline $\begin{array}{l}\text { Age (years) } \\
{[\operatorname{mean}(\mathrm{SD})]}\end{array}$ & $20.8(3.1)^{*+19}$ & $20.7(30)$ & $19.8(2.7)$ & $19.9(2.9)$ & $19.3(2.8)^{\mathrm{N} 0}$ & $19.7(3.2)$ & $\begin{array}{c}F(5,864)=6.30, \\
P=0.000\end{array}$ \\
\hline Gender (\% women) & $56.2^{+(N)}$ & 55.1 & $52.9^{+2 M}$ & $74.0^{*-1411)}$ & 65.2 & 56.0 & $\begin{array}{c}\chi^{2}(5)=12.13 \\
P=0.033\end{array}$ \\
\hline $\begin{array}{l}\text { Socio-economic } \\
\text { status of the parents } \\
\text { [mean (SD)] }\end{array}$ & $4.2(1.7)$ & $3.8(1.9)^{+M}$ & $4.4(1.7)$ & $4.8(1.6)$ & $4.8(1.5)^{+20}$ & $4.4(1.6)$ & $\begin{array}{c}F(5,837)=4.60, \\
P=0.000\end{array}$ \\
\hline \multicolumn{8}{|c|}{ Disease related characteristics of patents $(n=622)$} \\
\hline $\begin{array}{l}\text { Age of diagnosis } \\
\text { (years) Inean (SD)] }\end{array}$ & $(4.4)^{+15.2}$ & $11.5(7.3)^{+02010.9}$ & $0.2(1.7)^{+\infty .9 n \times M M}$ & 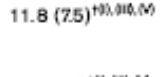 & 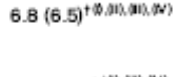 & - & $\begin{array}{l}F(4,600) \\
=159.05 \\
P=0.000\end{array}$ \\
\hline $\begin{array}{l}\text { Duration of disease } \\
\text { (years) Frean (SD)] }\end{array}$ & $(3.8)^{+50.7} .70 .0 \mathrm{~mm}$ & $9.3(6.4)^{+52.110}$ & $19.5(2.9)^{\mathrm{H}(0.9 \mathrm{~m} / \mathrm{m} / \mathrm{M})}$ & 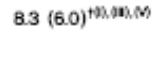 & $125(6.0)^{+5 n(20)(n)}$ & - & $\begin{array}{l}F(4,600) \\
=169.01 \\
P=0.000\end{array}$ \\
\hline Comorbidity (\% yes) & $29.4^{\text {tim) }}$ & $30.3^{+(*)}$ & $32.0^{+0 \mathrm{~V}}$ & 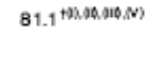 & $30.9^{\text {k(m) }}$ & - & $\begin{array}{c}P=0.000 \\
\chi^{2}(4)=71.76 \\
P=0.000\end{array}$ \\
\hline
\end{tabular}

$P \leq 0.01$ (twotaled) in comparson wh the contol group; ${ }^{\dagger} P \leq 0.01$ (two-taled) in comparison with the indicated diagnostic group.

Table 2 Labour participation in non-student patients and controls $(\%) G=331)$

\begin{tabular}{|c|c|c|c|c|c|c|c|}
\hline Number of hours per week & $\begin{array}{l}\text { Infammatory } \\
\text { bowel disease } \\
(n=122)\end{array}$ & $\begin{array}{c}\text { Chronic Ives } \\
\text { disease }(n=29)\end{array}$ & $\begin{array}{c}\text { Congenita } \\
\text { digestive disorder } \\
(n=43)\end{array}$ & $\begin{array}{l}\text { Food allergy } \\
\qquad(n=30)\end{array}$ & $\begin{array}{l}\text { Cellac disease } \\
\qquad(n=22)\end{array}$ & $\begin{array}{l}\text { Control group } \\
\qquad(n=85)\end{array}$ & $\begin{array}{c}\text { National stafstics }{ }^{a} \\
\quad(n=594061)\end{array}$ \\
\hline $\begin{array}{l}\text { 0-11 hot participaing in } \\
\text { labour make:t }^{\mathrm{b}}\end{array}$ & $23.0^{\circ}$ & $27.6^{\circ}$ & 9.3 & 23.3 & 9.1 & 11.8 & 9 \\
\hline 12-19 (parttime job) & 3.3 & 0.0 & 23 & 0.0 & 0.0 & 0.0 & 2 \\
\hline $\begin{array}{l}\text { Cumulative percentage, } \\
0-19 h^{\circ}\end{array}$ & $26.3^{* *}$ & $27.6^{\circ}$ & 11.6 & 23.3 & 9.1 & 11.8 & 11 \\
\hline 20-34 (part time job) & 22.1 & 27.6 & 25.6 & 33.3 & 18.2 & 21.2 & 21 \\
\hline $\begin{array}{l}\text { Cumulative percentage, } \\
0-34 \mathrm{~h}\end{array}$ & 48.4 & 55.2 & 37.2 & 56.6 & 27.3 & 330 & 32 \\
\hline$\geq 35$ (full-fime job) $^{\mathrm{d}}$ & $52.6^{\circ}$ & $44.8^{* *}$ & 628 & 43.3 & 72.7 & 67.1 & 68 \\
\hline Tota & 100 & 100 & 100 & 100 & 100 & 100 & 100 \\
\hline
\end{tabular}

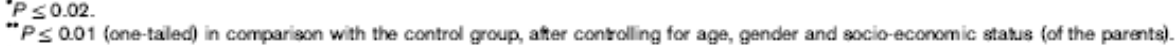

aStatstics Netheriands and Social and Cutura Planning Offce of The Netherlands $[13,14,20]$

Test: having a paid job ffrom $12 \mathrm{~h}$ ) versus not working $(0-11 \mathrm{~h}): \chi^{2}(5)=11.69, P=0.020$.

Test: having a pad job (from $12 \mathrm{~h}$ ) versus not working $(0-11 \mathrm{~h}): \chi^{2}(5)=11.69, P=0.020$.
Test: working from $20 \mathrm{~h}$ versus not working or 8 andl part-fime job $(0-19 \mathrm{~h}): \chi^{2}(5)=13.00, P=0.012$

Test: fulltime working (from $35 \mathrm{~h}$ ) versus not working or part-time working $(0-34 \mathrm{~h}): \chi^{2}(5)=11.49, P=0.021$.

Table 3 Burden of disease measures [mean scores (SD)] in non-student patients and controls $(n=344)$

\begin{tabular}{|c|c|c|c|c|c|c|c|}
\hline Measure (scale) & $\begin{array}{l}\text { Irftlammatory } \\
\text { bowel disease } \\
(n=126)\end{array}$ & $\begin{array}{c}\text { Chronic liver } \\
\text { deease }(n=30)\end{array}$ & $\begin{array}{c}\text { Congenital } \\
\text { digestive disorder } \\
(n=45)\end{array}$ & $\begin{array}{l}\text { Food allergy } \\
\qquad(n=24)\end{array}$ & $\begin{array}{l}\text { Coelac disease } \\
\quad(n=31)\end{array}$ & $\begin{array}{c}\text { Control group } \\
(n=88)\end{array}$ & Stafstics \\
\hline Physical complaints (0-46) & $9.2(6.6)^{* *}$ & $7.3(7.1)^{* *}$ & $5.8(5.5)$ & $12.5(7.5)^{* *}$ & $6.4(4.8)$ & $4.2(3.7)$ & $\begin{array}{c}F(5,321)=11.42, \\
P=0.000\end{array}$ \\
\hline Anxiety (0-21) & $5.8(4.3)$ & $7.7(4.9)^{*}$ & $5.7(4.8)$ & $6.5(4.3)$ & $4.3(4.0)$ & $4.5(3.7)$ & $\begin{array}{c}F(5,318)=3.42 \\
P=0.003\end{array}$ \\
\hline Depression $(0-21)$ & $3.6(3.4)$ & $4.9(3.9)^{-1}$ & $3.1(3.1)$ & $3.3(2.7)$ & $20(2.1)$ & $3.1(3.2)$ & $\begin{array}{c}F(5,319)=2.19 \\
P=0.028\end{array}$ \\
\hline Disablity in endurance $(0-6)$ & $2.4(2.2)^{*}$ & $2.2(2.0)^{* *}$ & $1.8(2.1)$ & $23(2.1)^{* *}$ & $1.1(1.3)$ & $1.3(1.5)$ & $\begin{array}{c}F(5,309)=3.76 \\
P=0.002\end{array}$ \\
\hline Hospitaization $(0-12)$ & $2.6(2.3)^{* *}$ & $3.0(2.6)^{*}$ & $4.0(3.0)^{*}$ & $1.5(1.4)$ & $1.8(1.3)$ & $1.4(1.6)$ & $\begin{array}{c}F(5,308)=9.27 \\
P=0.000\end{array}$ \\
\hline Use of medication (0-4) & $2.4(1.3)^{* *}$ & $1.2(1.4)^{*}$ & $0.6(1.1)$ & $1.3(1.1)^{*}$ & $0.2(0.4)$ & $0.2(0.6)$ & $\begin{array}{c}F(5,308)=49.34, \\
P=0.000\end{array}$ \\
\hline Need to diet adherence $(0-3)$ & $0.8(0.8)^{* *}$ & $0.7(0.8)^{\circ}$ & $0.6(0.8)$ & $20(0.7)^{*}$ & $2.7(0.9)^{* *}$ & $0.4(0.7)$ & $\begin{array}{c}F(5,322)=41.24, \\
P=0.000\end{array}$ \\
\hline Tolet use $(0-4)$ & $1.1(1.2)^{* *}$ & $1.0(1.1)^{* *}$ & $0.7(0.9)$ & $0.7(0.9)$ & $0.1(0.4)$ & $0.5(0.9)$ & $\begin{array}{c}F(5,321)=5.02 \\
P=0.000\end{array}$ \\
\hline
\end{tabular}

$P \leq 0.02$

${ }^{*} P \leq 0.01$ (onetaled) compared with controls, after controling for age, gender and socio-economic status of the parents. 
Calsbeek, H., Rijken, M., Dekker, J., Berge Henegouwen, G.P. van. Disease characteristics as determinants of the labour market position of adolescents and young adults with chronic digestive disorders. European Journal of Gastroenterology \& Hepatology: 2006, 18(2), 203-209

Table 4 Relation (bivariate logistic regression analyses) between burden of disease measures and labour participation in non-student patients $(n=246)$

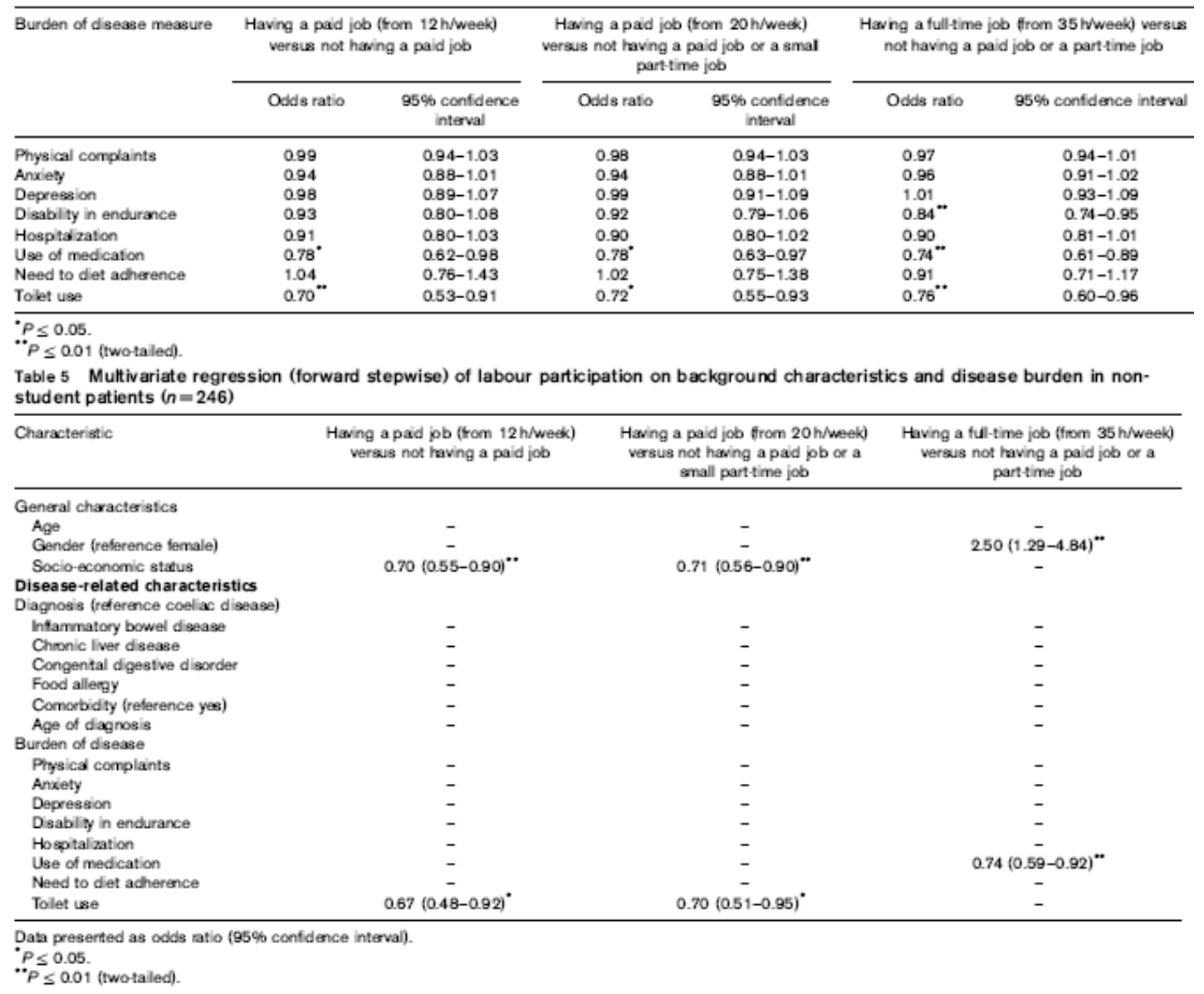

